\title{
Expanding the Innovation Practice Education to College Students from a Key Point
}

\author{
Yubo Liu, Xinkuan Liu*, Xiao Liu,Tianhao Zhu, Zhaorong Shi, Deng-Guang Yu \\ School of Materials Science and Engineering, University of Shanghai for Science and Technology \\ 516 Jungong Road, Shanghai 200093, China \\ E-mail: xinkuanliu@163.com
}

\begin{abstract}
The innovation practice capability is one of the most important factors that determines the college students' comprehensive qualities. However, how to improve students' innovation practice capability is a major issue to their teachers. In this report, a strategy is shown on how to train students. Starting from a key point - one kind of advanced nanotechnology (electrospinning), the college students can effectively experience the whole processes of theoretical education about fundamental knowledge, engineering education about working process of electrospinning, and data treatment and paper writing education. After this kind of scientific innovation education, the students should understand some key aspects and the right way about how to improve their practice capability, how to carry out the innovation practice, and how to improve their comprehensive quality.
\end{abstract}

Keywords-Scientific practice education; Innovation practice education; College students; Engineering education; Electrospinning

\section{INTRODUCTION}

Today, it is recognized that the innovation practice capability comprises one of the most important factors that determines the college students' comprehensive qualities. Shown in Fig. 1, a series of elements are often applied to evaluate the students' comprehensive quality. These elements include: 1) physical quality and mental quality, which ensure that they are health natural persons; 2) political and ideological quality, which ensure that they are social and normal person; and 3) professional, labor skill, and innovation quality, which determine their qualities and make them different with others in generating public wealth.

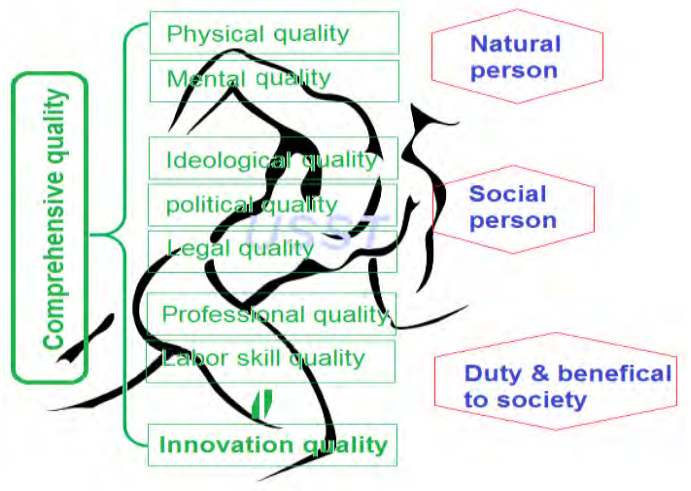

Fig. 1 The elements to evaluate the students' comprehensive quality.
Correspondingly, innovation practice education is becoming a very important sector for fostering the college students' innovation capability and comprehensive quality to become outstanding talents. But how to implementing effective innovation practice education often puzzles their teachers a lot in their lessons. Scientific researches are one complicated practice activity, during which both fundamental knowledge and also innovative thoughts are needed. Thus, scientific practice can be viewed as an advanced practice and should be useful for innovation practice educations. Certainly, because it is too broad and complicated for a college student who is a new hand in his scientific area, thus, starting from a key point of the scientific contents to expand the innovation practice education on the college students should be an efficacious manner for innovation practice education.

In the scientific practice training, the several important components should include (Fig. 2): 1) the theoretical education about the professional knowledge; 2) the engineering education; 3) the professional education; 4) paper writing education; and some other educations such as safety education, competence education, and education of laws and regulations. Within all these education, a certain advanced technology can often be reasonably selected to provoke the students' interests on scientific practice training and further to start and expand the innovation practice training.

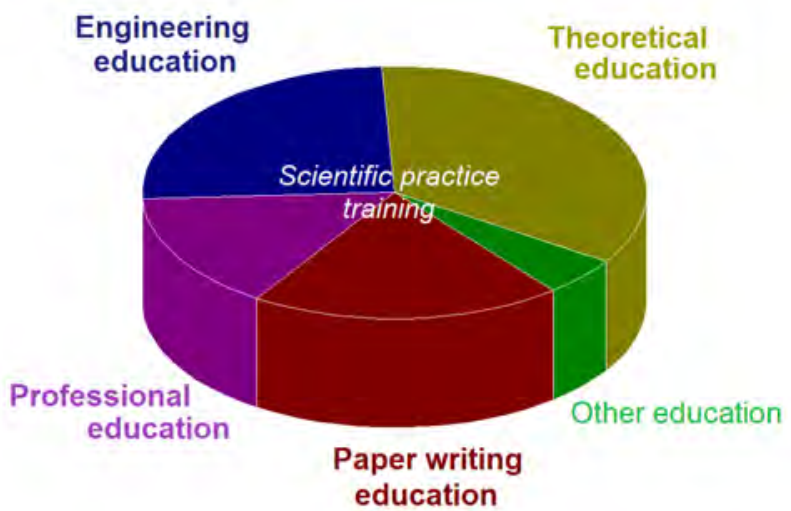

Fig. 2 The components of scientific practice training.

Here, based on the implementation of an advanced nanofabrication technology-electrospinning, an example is exhibited on how to conduct the scientific practice education. Electrospinning has abundant teaching materials for all types 
of innovation educations to the college students, such as scientific research education, theoretical education, engineering education, data treatment and paper writing education [1-7].

\section{ELECTROSPINNING HAS ABUNDANT TEACHING}

\section{MATERIALS FOR ALL TYPES OF INNOVATION EDUCATIONS TO}

\section{COLLEGE STUDENTS}

There are numerous publications in literature about electrospinning and also the electrospun nanofibers [8-11]. Meanwhile, many schematic diagrams can be found to explain this advanced technology [12-14]. One of the most vivid representatives is show in Fig. 3, which can be found in https:/en.wikipedia.org/wiki/Electrospinning. In this figure, three groups of variables are concluded as 1) solution variables; 2 ) needle variables and 3) collector variables [15-17]. Through the effective interactions between the electrostatic energy and the working fluids, many vivid teaching materials can be extracted for the college students, which include theoretical education about electrohydrodynamic atomization mechanism, operation parameters and the related engineering education, characterization of advanced nanomaterials and the later data treatment and paper writing education. These contents can be transferred to the students before they carry out the electrospinning experiments themselves.

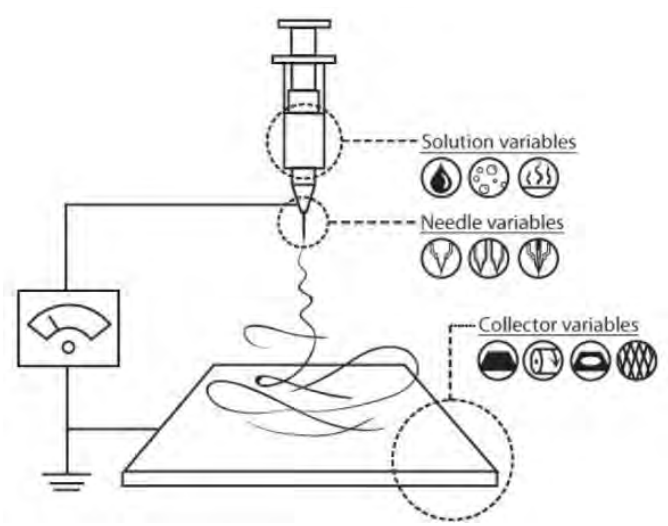

Fig. 3 A typical schematic of the electrospinning process.

\section{THEORETICAL EDUCATION ON FUNDAMENTAL KNOWLEDGE}

In a natural sense, electrospinning and electrospraying are "brother" technologies. Both of them mainly start from polymer solutions, pass through the electrical energy-liquid interactions to evaporate the solvent, and finally achieve solid products at the micro- or nano- scale [18-23]. The two important knowledge points are the formation of Taylor cone and the high frequently bending and whipping processes, during which the solvents escape to the environment, leaving a solid product [24-26]. The formation of Taylor cone is a perfect balance of electrical drawing forces and the surface tensions o the working liquids (Fig. 4). The drying processes of the working fluid have a close relationship with the interfaces between the atmosphere and the working liquid, i.e. the well-known Knudsen layer in Fig. 4.

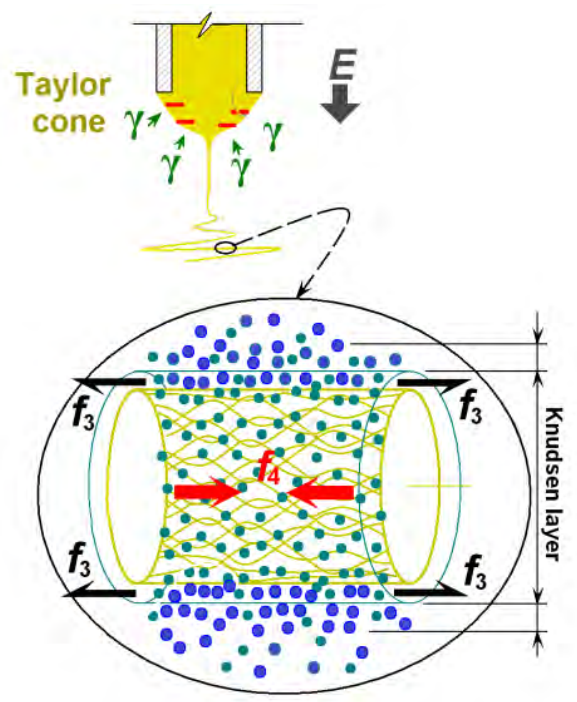

Fig. 4 The most important key fundamental points in electrospinning--the formation of Taylor cone of fluid and the fluid-energy interactions

These theoretical educations can make the students clear about the essences of electrospinning, and also other electrohydrodynamic atomization processes such as electrospraying and e-jet printing. What is more, these contents for education should make the practice education more facile and easier, and from which innovation practice education and innovation behaviors may be drawn out step-by-step during the teaching processes.

\section{ENGINEERING EDUCATION - THE WORKING PROCESS OF ELECTROSPINNING}

Innovation practice education is apparently a further step from the convergent point of engineering education and practice education. During the practice education processes, the engineering education can be carried out to the students simultaneously with the important parameters as teaching materials (Fig. 5). In the electrospinning practice, three categories of parameters will play their roles for imparting engineering knowledge and the potential innovative ideas to the college students. For example, in the preparation of suitable working fluids, a series of variables including polymer concentration, additive, surface tension, conductivity and rheology can be exploited for new trials. Similarly, a wide variety of parameters for operation (applied voltage, flow rate, and collect distance) and about the environment (humidity, temperature and vacuum) can be innovatively explored to manipulate the fluid-energy interactions, and thus in turn to generate new kinds of nanomaterials [27-29]. 


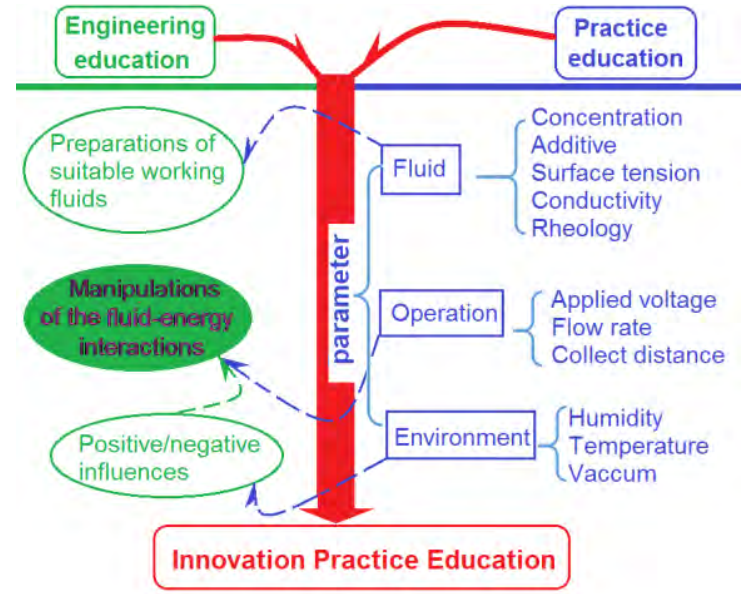

Fig. 5 The key point - working fluid for initiating and expanding the engineering and practice educations

\section{DATA TREATMENT AND PAPER WRITING EDUCATION}

For the college students' comprehensive quality and particularly the innovation practice ability, their capability of treating experimental data, processing graphics and writing reports is also a very important section. After the scientific practice, they should know that a scientific report or a research paper is composed of several integrant parts. Through these parts, the practice processes can be recorded first, and later through comparison and conclusion, innovative ideas and possible novel methods or materials may be drawn out from these processes.

Typically, the final section of a whole scientific practice education, i.e. data treatment and paper writing education, can provide useful feedback information for the previous jobs. Shown in Fig. 6, the feedback information can give ideas about the selections of raw materials, the selections of processing methods, the optimization of working parameters, and the analyses of the experimental results. After several times of practices, the college students should experience a "practice makes perfect" process and improve their innovation capability.

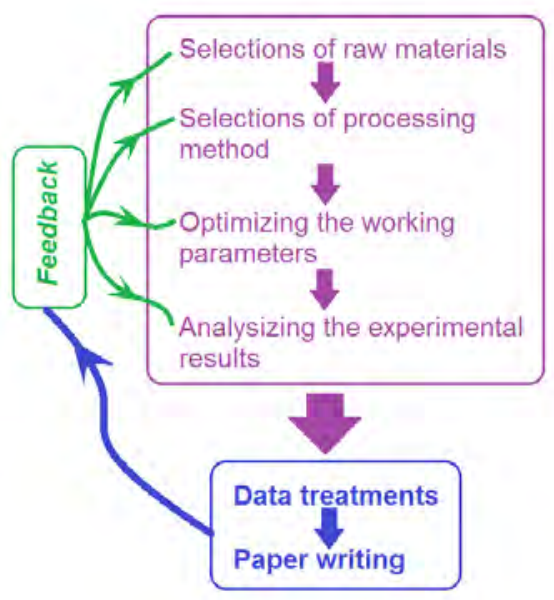

Fig. 6 The final section of a whole scientific practice education - data treatment and paper writing education

\section{SUMMARY}

The advanced technologies often have abundant teaching materials for all types of educations to college students. In this report, with electrospinning as an example and a start point, we have discussed how to progress from the theoretical education about fundamental knowledge, to the engineering education about the working process of electrospinning, and to the data treatment and paper writing education. Through the training of a whole scientific innovation practice, it is believed that the college students should understand that the essence of innovation practice is a new and further step from "skilled" practices, and are soberly aware of fostering their life-long learning capability to improve their comprehensive quality.

\section{ACKNOWLEDGMENT}

The financial supports are from theShanghai Education Science Research Project (C17058) and the National Nature Science Foundation of China (51373101).

\section{REFERENCES}

[1] D.G. Yu,J.J. Li,G.R. Williams, and M. Zhao, "Electrospun amorphous solid dispersions of poorly water-soluble drugs: A review,"J. Control. Release, vol. 292, pp.91-110, 2018.

[2] D.G. Yu, C. Yang, M. Jin, G.R. Williams, H. Zou, X. Wang, et al, "Medicated Janus fibers fabricated using a Teflon-coated side-by-side spinneret," Colloid. SurfaceB, vol.138, pp.110-116, Feburary 2016.

[3] Y.H. Wu, D.G. Yu, H.P. Li, X.Y. Wu, and X.Y. Li, "Medicated structural PVP/PEG composites fabricated using coaxial electrospinning," e-Polymers, vol.17, pp.39-44, January 2017.

[4] C. Yang, D.G. Yu, D. Pan, X.K. Liu, X. Wang, S.W.A. Bligh, et al, "Electrospun pH-sensitive core-shell polymer nanocomposites fabricated using a tri-axial processes," Acta Biomater., vol.35, pp.77-86, April 2016.

[5] D.G. Yu, X. L. Zheng, Y. Yang, X. Y. Li, G.R. Williams, M. Zhao, "Immediate release of helicid from nanoparticles produced by modified coaxial electrospraying," Appl. Surf. Sci., 2019 (In publication).

[6] Y.Y. Yang, Z.P. Liu, D.G. Yu, K. Wang, P. Liu, X. Chen, "Colon-specific pulsatile drug release provided by electrospun shellac nanocoating on hydrophilic amorphous composites," Int. J. Nanomed., vol.2018, pp. 2395-2404, 2018.

[7] Q. Wang, D.G. Yu, L.L. Zhang, X.K. Liu, Y.C. Deng, and M. Zhao, "Electrospun hypromellose-based hydrophilic composites for rapid dissolution of poorly water-soluble drug," Carbohydr. Polym., vol.174, pp.617-625, Oct, 2017.

[8] Y. Yang,W. Li,D.G. Yu,G. Wang,G.R. Williams, Z. Zhang, "Tunable drug release from nanofibers coated withblankcellulose acetate layers fabricated usingtri-axial electrospinning," Carbohydr. Polym., vol.203, pp.228-237, 2019.

[9] K. Wang, X.K. Liu, X.H. Chen, D.G. Yu, Y.Y. Yang, and P. Liu, "Electrospun hydrophilic Janus nanocomposites for the rapid onset of therapeutic action of helicid,"ACS Appl. Mater. Interfaces, vol.10, pp.2859-2867, 2018.

[10] G.Z. Yang, J.J. Li, D.G. Yu, M.F. He, J.H. Yang, and G.R. Williams, "Nanosized sustained-release drug depots fabricated using modified tri-axial electrospinning," Acta Biomater., vol.53, pp.233-241, April 2017.

[11] Y. Xu, J.J. Li, D.G. Yu, G.R. Williams, J.H. Yang, and X. Wang, "Influence of the drug distribution in electrospun gliadin fibers on drug-release behavior," Eur. J. Pharm. Sci., vol.106, pp.422-430, August 2017.

[12] Z. Zhang, W. Li, G. Wang, Y.L. Qu, and D.G. Yu, "Electrospun 4th generation solid dispersions of poorly water-soluble drug utilizing two different processes," J. Nanomater. Vol.2018, Article ID 2012140, 2018 . 
[13] Q. Wang, D.G. Yu, S.Y. Zhou, C. Li, and M. Zhao, "Fabrication of amorphous electrospun medicated-nanocomposites using a Teflon-based concentric spinneret," e-Polymer, vol.18, pp.3-11, 2018.

[14] H.F. Wen, C. Yang, D.G. Yu, X.Y. Li, D.F. Zhang, "Electrospun zein nanoribbons for treatment of lead-contained wastewater," Chem. Eng. J., vol.290, pp.263-272, 2016.

[15] D.G. Yu, J.J. Li, M. Zhang, and G.R. Williams, "High-quality Janus nanofibers prepared using three-fluid electrospinning," Chem. Commun., vol.53, pp.4542-4545,April 2017.

[16] M. Jin, D.G. Yu, X. Wang, C.F.G.C. Geraldes, G.R. Williams, and S.W.A. Bligh, "Electrospun contrast agent-loaded fibers for colon-targeted MRI,” Adv. Healthcare Mater., vol.5, pp.977-985, April 2016.

[17] T. Hai, X. Wan, D.G. Yu, K. Wang, Y. Yang, Z.P. Liu, "Electrospun lipid-coated medicated nanocomposites for an improved drug sustained-release profile,” Mater. Design, vol.162, pp.70-79, 2019.

[18] X.Y. Li, Z.B. Zheng, D.G. Yu, X.K. Liu, Y.L. Qu, andH.L. Li, "Electrosprayed sperical ethylcellulose nanoparticles for an improved sustained-release profile of anticancer drug," Cellulose, vol.24, pp.5551-5564, 2017.

[19] Y.Y. Yang, M. Zhang,K. Wang, and D.G. Yu, "pH-sensitive polymer nanocoating on hydrophilic composites fabricated using modified coaxial electrospraying," Mater. Lett., vol.227, pp. 93-96, 2018.

[20] Y.Y. Yang, M. Zhang, Z.P. Liu, K. Wang, andD.G. Yu, "Meletin sustained-releasegliadin nanoparticles prepared via solvent surface modification on blending electrospraying,"App. Surf. Sci., vol.434, pp.1040-1047, 2018.

[21] Liu, W. Shao, M. Luo,J. Bian,D.G. Yu, "Electrospun blank nanocoating for improved sustained release profiles from medicated gliadin nanofibers,"Nanomaterials, vol.8, Article ID 184 (11 pages), 2018.

[22] Z.P. Liu, Y.Y. Zhang, D.G. Yu, D. Wu, andH.L. Li, "Fabrication of sustained-release zein nanoparticles via modified coaxial electrospraying," Chem. Eng. J., vol.334, pp.807-816, 2018.

[23] W. Huang, Y. Yang, B. Zhao, G. Liang, S. Liu, X.-L. Liu, and D.G. Yu, "Fast dissolving of ferulic acid via electrospun ternary amorphous composites produced by a coaxial process," Pharmaceutics, vol.10, Article ID115 (12 pages), 2018

[24] K. Wang, H.F. Wen, D.G. Yu, Y. Yang, and D.F. Zhang, "Electrosprayed hydrophilic nanocomposites coated with shellac for colon-specific delayed drug delivery," Mater. Design, vol.143, pp.248-255, 2018.

[25] Z.P. Liu, L.L. Zhang, Y.Y. Yang, D. Wu,G. Jiang, andD.G. Yu, "Preparingcomposite nanoparticles for immediate drug release by modifying electrohydrodynamic interfaces during electrospraying," Powder Technol., vol.327, pp.179-187, 2018.

[26] Liu, Y. Yang, D.G. Yu, M.J. Zhu, M. Zhao, G.R. Williams, "Tunable zero-order drug delivery systems created by modified triaxial electrospinning," Chem. Eng. J., vol. 356, pp.886-694, 2019.

[27] J.J. Li, Y.Y. Yang, D.G. Yu, Q. Du, X.L. Yang, "Fast dissolving drug delivery membrane based on the ultra-thin shell of electrospun core-shell nanofibers,"Eur. J. Pharm. Sci., vol.107, pp. 195-204, 2018.

[28] Y. Yang,W. Li,D.G. Yu,G. Wang,G.R. Williams, Z. Zhang, "Tunable drug release from nanofibers coated withblankcellulose acetate layers fabricated usingtri-axial electrospinning," Carbohydr. Polym., vol.203, pp.228-237, 2019.

[29] M. Jin, D.G. Yu, C.F.G.C. Geraldes, G.R. Williams, and S.W.A. Bligh, "Theranostic fibers for simultaneous imaging and drug delivery," Mol. Pharm., vol.13, pp.2457-2465, July 2016. 